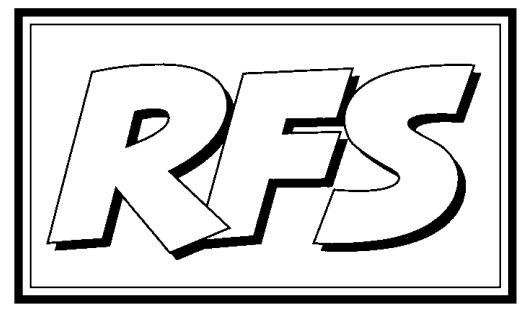

Revista de Fomento Social, 55 (2000), 189-218

\title{
El Área de Libre Comercio de las Américas y las relaciones de Estados Unidos con América Latina en la posguerra fría. Abriendo puertas, cerrando heridas
}

Antonio Luis HIDALGO CAPITÁN ${ }^{1}$

Hace poco más de un siglo, España fue vencida en la guerra hispanoamericana por Estados Unidos, perdiendo con ello no sólo la última colonia americana, Cuba, sino también lo que quedaba de su papel de potencia hegemónica en la región. Por el contrario, Estados Unidos daba el paso decisivo para consolidarse como la potencia hegemónica del orden neocolonial de las Américas.

1 Doctor en Ciencias Económicas y Profesor del Departamento de Economía e Historia de las Instituciones Económicas de la Universidad de Huelva. El autor agradece a Ana Patricia Cubillo Guevara su colaboración en la búsqueda de documentación, en la revisión y en la corrección de este documento. 
Tomando como referencia 1898, podemos afirmar que el siglo XX ha sido el Siglo del Imperialismo Americano. Bajo la filosofía de América para los americanos, recogida en la Doctrina Monroe, Estados Unidos consiguió consolidar un imperio en el hemisferio americano y, como en todos los grandes imperios de la historia, la política, la economía y la cultura se intentaron dictar desde la metrópoli.

En todo este siglo los sentimientos de los latinoamericanos hacia Estados Unidos han sido mayoritariamente adversos, por su talante imperialista, mientras que éstos consideraban a la región como el "patio trasero" de su casa, donde el comunismo podía crecer como una mala hierba. Las relaciones entre la región y el vecino del norte no mejoraron hasta que el American Way of Life fue transformando su cultura, en virtud de la globalización de las comunicaciones, y este país comenzó a ver la región como el gran mercado que puede permitirle mantener su poder económico frente a la Unión Europea o Japón.

La Iniciativa para las Américas de Bush fue la primera piedra para la constitución del bloque comercial que será el Área de Libre Comercio de las Américas (ALCA). Ante la perspectiva de un mundo globalizado y policéntriCo, las grandes potencias de la segunda mitad del siglo XX se han dispuesto a defender su hegemonía aunque sea en un área geográfica regional. De todos Ios posibles bloques comerciales que se perfilan en la geopolítica del XXI, el ALCA es el que por el momento se aprecia con mayor nitidez.

\section{EL CAMBIO DE ACTITUD EN LAS RELACIONES HEMISFÉRICAS Y SUS CONSECUENCIAS EN LA INTEGRACIÓN REGIONAL}

A finales de la década de los ochenta, el orden internacional sufrió un cambio repentino y fundamental, el fin de la Guerra Fría. En la URSS había triunfado la perestroika de Gorbachov, el Muro de Berlín se derrumbó, el ejército soviético se retiró de Europa Oriental, la República Democrática Alemana se incorporó a una Alemania "reunificada" y el resto de los países de la Europa del Este se sumergieron en procesos de transición política y económica.

Esta situación redujo el temor de Estados Unidos a la propagación del comunismo en la región, por lo que su actitud imperialista se suavizó; fruto de ello fue la Iniciativa para las Américas. Por su parte, los países latinoamericanos, ante el duro aprendizaje de la década perdida, tomaron conciencia 
de que sus relaciones económicas con Estados Unidos les aportaban más beneficios que perjuicios, y el término "dependencia" fue siendo sustituido por el de "interdependencia"; en este sentido destacan las palabras de Raúl Prebisch, meses antes de su muerte en 1986, cuando afirmaba: "El poder hegemónico de los Estados Unidos es un hecho que no nos es dado cambiar. Puede ejercerse en dos formas: una es dejar los acontecimientos latinoamericanos a la deriva y afrontar los trastornos consiguientes con medidas punitivas o el empleo de la fuerza; la otra es practicar una política previsora y esclarecida de interdependencia positiva. No hay otras opciones" (Prebisch, 1988, p. 212). Fruto de este cambio de actitud es la propuesta latinoamericana de la Transformación Productiva con Equidad, Ianzada en 1990 por la CEPAL bajo la influencia de Fernando Fajnzylber, y de la que el Regionalismo Abierto es uno de sus desarrollos en los años noventa.

Inspirados en estos nuevos enfoques se han revitalizado al gunos procesos de integración existentes en América Latina y han proliferado nuevos esquemas a caballo entre la liberalización comercial y la integración económica.

\subsection{La Iniciativa para las Américas y el Regionalismo Abierto}

En 1990, en concordancia con el liberalismo económico imperante, el Presidente de Estados Unidos, George Bush, Ianzó Ia Iniciativa para las Américas, un ambicioso programa, no de integración regional propiamente dicha, sino de creación de un área de libre comercio desde Alaska hasta Tierra de Fuego. Se trataba de favorecer los intercambios comerciales entre todos los países del hemisferio americano bajo la filosofía del libre comercio y sin pretensiones de integración regional supranacional.

El programa, que había sido elaborado por el Secretario del Tesoro, Nicolás Brady, tenía dos importantes antecedentes en los que se inspiraba, y un complemento; los dos primeros son el Plan Brady, de 1989, para reducir la deuda externa latinoamericana, y la Iniciativa para la Cuenca del Caribe, de 1984, una zona de libre comercio unilateral entre Estados Unidos y esta región; el complemento es el Ilamado Consenso de Washington.

El Plan Brady fue una estrategia, que reemplazó al fracasado Plan Baker, para reducir la deuda externa latinoamericana y su servicio. Este plan se basaba en tres puntos cuya ejecución no dependía de Estados Unidos: el primero era la asignación de recursos públicos, por parte del FMI y el Banco Mundial, para apoyar las operaciones de reducciones de deuda; el segundo 
era la supresión de la condicionalidad cruzada por medio de la cual los acuerdos para reducir la deuda estaban vinculados a la adopción de los programas de estabilización y ajuste recomendados por el FMI y el Banco Mundial; y el tercero era la modificación de las legislaciones de los países donde se ubicaba la banca acreedora para propiciar las reducciones de la deuda.

La Iniciativa para la Cuenca del Caribe estaba constituida por un conjunto de medidas económicas destinadas a reforzar la estabilidad política de los países de la región, que trataban de consolidar sus democracias y alejarse de las situaciones de guerra. La iniciativa tenía tres vertientes, un monto de 350 millones de dólares para cubrir déficits de la balanza de pagos, descuentos tributarios y una zona unilateral de libre comercio, por medio de la cual estos países aprovechaban un conjunto de franquicias que les permitían introducir sus productos en Estados Unidos.

El complemento de la Iniciativa para las Américas lo constituyó el Ilamado Consenso de Washington ${ }^{2}$, una síntesis de las propuestas de corte neoliberal de los organismos internacionales con sede en Washington (FMI y Banco Mundial), de la Casa Blanca, de los ministros de economía del G-7 y de los presidentes de los veinte mayores bancos privados internacionales. Este consenso versaba sobre la naturaleza de la crisis latinoamericana y sobre las reformas que debían aplicarse para superarla, que no eran otras que políticas de estabilización y de ajuste estructural, basadas en la consecución de un equilibrio macroeconómico estable y en la adopción de un modelo de desarrollo orientado hacia el mercado (reducción del Estado, liberalización del comercio internacional y promoción de las exportaciones). La consideración de elemento complementario se debe a que la aceptación de las recomendaciones de dicho consenso fue establecida como un requisito para participar en la Iniciativa para las Américas.

La propuesta de Bush se articulaba en tres ejes, deuda, inversiones y comercio. El primero añadía poco más al Plan Brady presentado un año antes, tan sólo la reducción de la deuda oficial bilateral con Estados Unidos y la incorporación del Banco Interamericano de Desarrollo como fuente de recursos públicos para la reducción del resto de la deuda; sin embargo,

2 Véase: Josep F. MÀriA (2000), «El Consenso de Washington. ¿Paradigma económico del capitalismo triunfante?». En Revista de Fomento Social, Córdoba, Publicaciones ETEA, №217, 55, enero-marzo, págs. 29-46 (Nota de la redacción). 
para acogerse a estas medidas se requería que los deudores hubiesen firmado acuerdos de reforma económica o con el Banco Mundial, o con el FMI, o con el BID, o que hubiesen negociado reducciones de deuda con la banca comercial. Por lo que se refiere a las inversiones en la región, Estados Unidos aportaría 100 millones de dólares anuales, administrados por el BID, e intentaría que la Unión Europea y J apón hicieran lo mismo; dichos fondos estarían destinados a financiar aquellas reformas que dieran mayor protagonismo al mercado, que fomentaran las privatizaciones y que redujeran las limitaciones a las inversiones extranjeras en la región. Con estos dos ejes se pretendía que los países que participaran de la propuesta tuvieran sus economías saneadas y hubiesen aceptado los postulados neoliberales del Consenso de Washington.

Sin embargo, el tercer eje, el comercial, era el más relevante y el que importaba realmente a Estados Unidos. Se articulaba en dos propuestas; la primera, el apoyo mutuo en la Ronda Uruguay del GATT, que entonces se estaba negociando, de forma que el libre comercio saliera fortalecido y que los productos latinoamericanos obtuvieran reducciones arancelarias mayores; la segunda, la conformación de una zona hemisférica de libre comercio. Este área se iría configurando lentamente a partir de la firma de acuerdos marco donde se sentarían las bases de las futuras negociaciones; en este proceso se daría preferencia a los países que estuvieran organizados en esquemas de integración y que, por tanto, estuvieran comprometidos con la liberalización comercial, ya que, a diferencia de la Iniciativa para la Cuenca del Caribe, Ia Iniciativa para las Américas suponía reducciones arancelarias bilaterales, eliminación de barreras no arancelarias, protección de los derechos de propiedad intelectual, fomento del libre comercio de bienes y servicios, fomento deflujos financieros y procedimientos rápidos e imparciales para la resolución de conflictos.

La importancia de la Iniciativa para las Américas no reside tanto en su contenido, cuyo grado de desarrollo es cuestionable, sino en el cambio de actitud que supuso por parte de Estados Unidos en lo que se refiere a sus relaciones con América Latina. Frente al imperialismo norteamericano de la primera mitad del siglo XX y, sobre todo, de la Guerra Fría, los años noventa han estado marcados por una actitud más próxima al panamericanismo; la propuesta de abrir el mercado norteamericano a los productos del América Latina parece responder a la vieja reivindicación de cooperación al desarrollo Trade, NotAid, mientras que los esfuerzos por solucionar el problema de la deuda, reactivar las inversiones en la región y mantener 
una postura común en las negociaciones del GATT, igualmente resultaron beneficiosas para América Latina. Esto no quiere decir que Estados Unidos no obtuviera ningún provecho de la propuesta (reserva preferente del mercado latinoamericano, apoyo al sistema financiero norteamericano, mayor implantación regional de las empresas norteamericanas, reactivación de la demanda latinoamericana de productos norteamericanos, erosión del proteccionismo agrícola de la Unión Europea...), sino que dichos beneficios parecen ahora legítimos. En poco se parece la nueva actitud norteamericana a la que inspiró las intervenciones más o menos directas en los asuntos internos de los países latinoamericanos y caribeños (Cuba, Panamá, Chile, Nicaragua, El Salvador, J amaica, Granada...). Sin embargo, parece igualmente claro que detrás de esta propuesta hay una id eología, el neoliberalismo, auténtica amenaza para el desarrollo latinoamericano durante el siglo XXI, para unos, y el fin del tercermundismo en América Latina para otros.

Al margen de este cambio de actitud, la Iniciativa para las Américas ha tenido también importantes consecuencias en relación con la integración comercial en toda la región. El primer fruto de esta propuesta fue la firma del Acuerdo de Libre Comercio de América del Norte (NAFTA); el segundo, la proliferación de acuerdos bilaterales y multilaterales de libre comercio y la revitalización de viejos esquemas de integración; y el tercero, las negociaciones para la constitución del Área de Libre Comercio de las Américas (ALCA).

La filosofía librecambista que ha impregnado todos estos acuerdos comerciales fue sintetizada por la CEPAL en 1994 en su propuesta de Regionalismo Abierto, expresión con la que se quiere compatibilizar la apertura comercial generalizada de los países latinoamericanos con el trato preferencial que se otorga bajo el arrope de un proceso de integración. Esta propuesta forma parte del desarrollo de la Transformación Productiva con Equidad, síntesis del pensamiento neoestructuralista latinoamericano. Aunque herederos de la tradición cepalina, los neoestructuralistas de los noventa fueron capaces de romper con los viejos esquemas del proteccionismo y de la dependencia, viendo en el comercio exterior no sólo una forma de reactivar unas economías en crisis sino un eficaz elemento de desarrollo. El libre comercio, la promoción de exportaciones y el acceso al mercado norteamericano han sustituido en los esquemas mentales de los neoestructuralistas al proteccionismo, a la sustitución de importaciones y al desarrollo del mercado doméstico. 
Bajo este nuevo marco, los neoestructuralistas de la CEPAL apuestan por formas de integración flexibles que busquen la intensificación del libre comercio tratando de aprovechar las ahora reconocidas ventajas del mismo; es decir, apuestan por formas de integración, que respetando el libre comercio mundial, hagan éste aún más libre dentro del área de integración y cuyo desarrollo institucional venga marcado por las exigencias del mercado. Se trata de compatibilizar la liberalización de las relaciones económicas exteriores (comerciales y financieras) a nivel mundial con los acuerdos de integración regional. La propuesta se basa en modelos de integración más liberalizadores que las tendencias internacionales; por ejemplo, una reducción arancelaria generalizada de mayor intensidad dentro del área de integración. Con esta estrategia se contribuye a elevar la competitividad internacional, por la vía de la liberalización, sin perjudicar la integración regional e incluso hemisférica, donde el ingrediente preferencial es esencial.

El Regionalismo Abierto requiere además: una liberalización amplia de sectores y de países; una estabilidad macroeconómica de éstos; adecuados mecanismos de pagos y de comercio; la construcción de infraestructura; la armonización de normas comerciales, regulaciones internas, estándares y normas laborales y de inmigración; un arancel exterior común moderado; el refuerzo de los organismos regionales de apoyo a la balanza de pagos; mecanismos rápidos de consulta y resolución de conflictos; las políticas de defensa de la competencia; y esquemas flexibles de integración, de forma que la dinámica del proceso imponga el ritmo del desarrollo institucional.

Nada tiene que ver, por tanto, esta propuesta de integración con la que CEPAL impulsó en los años cincuenta y sesenta en toda la región como una forma de ampliar la dimensión de los mercados domésticos protegidos por la política de industrialización por sustitución de importaciones. Los neoestructuralistas, con la esperanza de que la inserción en un mercado global sea beneficiosa para las economías de la región, defienden una política de puertas abiertas que contrasta con la política de puertas cerradas de los viejos estructuralistas, convencidos de que la inserción internacional de las economías latinoamericanas eran las responsables del subdesarrollo y la dependencia de las mismas. Este acercamiento de los postulados neoestructuralistas de la CEPAL a los postulados neoliberales del FMI y del Banco Mundial ha hecho que muchos vean en ello una claudicación de la que fuera una fortaleza de la economía heterodoxa ante las fuerzas del pensamiento único. 
Como puede apreciarse, el fin de la Guerra Fría ha traído un nuevo clima de panamericanismo a la región, en el que las partes, Estados Unidos y los países latinoamericanos, han ido acercando posiciones, con la excepción hecha de Cuba, que parece decidida a entrar en el siglo XXI defendiendo las ideas de un socialismo que surgió en el siglo XIX. Sin embargo, a pesar de este panamericanismo reinante, no han faltado gestos imperialistas por parte de Estados Unidos, como la invasión de Panamá, para secuestrar a Noriega, o la promulgación de la Ley Helms-Burton, para dificultar las relaciones económicas de Cuba con el resto del mundo. También en América Latina siguen existiendo colectivos que defienden la confrontación con Estados Unidos, pero éstos carecen hoy día de influencia política, destacando en muchos casos tan sólo por practicar la lucha armada (grupos guerrilleros colombianos, peruanos, mexicanos...).

\subsection{Los procesos de integración del hemisferio americano en los noventa}

Desde que Simón Bolívar lanzara la idea del panamericanismo, muchos han sido los procesos de integración regional iniciados y muy pocos los logros cosechados. Como hemos mencionado, la integración regional cobró protagonismo cuando, en los años cincuenta, la CEPAL la recomendó como parte de la estrategia de industrialización por sustitución de importaciones; surgieron así, y se fueron consolidando durante la décadas de los sesenta y setenta, varios procesos de integración entre diferentes países del continente americano y del Caribe (ALALC, Pacto Andino, MCCA, CARIFTA). Sin embargo, los nacionalismos existentes, el agotamiento del modelo de industrialización por sustitución de importaciones y la crisis de la deuda, terminaron por erosionar los logros alcanzados en décadas anteriores y pusieron en cuestión las bondades de la integración regional.

Ya en los noventa y bajo el paraguas de la propuesta de Bush, se fueron constituyendo nuevos procesos de integración y revitalizando otros ya existentes. Sin embargo, como se recogía en el Regionalismo Abierto de la CEPAL, la integración ha de hacerse al ritmo que marque el mercado, por lo que la mayoría de los procesos se están basando en acuerdos de libre comercio, siguiendo el modelo del firmado entre Canadá y Estados Unidos (NAFTA), al que se adhirió México a principios de los noventa y al que Chile ha intentado adherirse, sin éxito hasta el momento.

EI NAFTA es un acuerdo a caballo entre la integración y el libre comercio. 
Como acuerdo de libre comercio, y siguiendo los esquemas que recogen los manuales de integración, puede ser considerado como la primera fase de un proceso de integración regional; sin embargo, los países firmantes no parecen querer ir más allá de esta primera fase, lo que pone en cuestión la idea de que se trate realmente de un "proceso de integración" y refuerza la tesis de que es tan sólo un acuerdo de liberalización comercial de ámbito geográfico restringido.

Frente al modelo que representa el NAFTA, aunque con la misma filosofía del libre comercio, tenemos el Mercosur, un tratado de libre comercio firmado a principios de los noventa entre Argentina y Brasil, al que luego se adhirieron Uruguay y Paraguay. El Mercosur sí ha nacido con la aspiración de convertirse con el tiempo en un esquema de integración regional que supere la fase de libre comercio para avanzar hacia un verdadero mercado común del sur.

Así mismo, durante los noventa se han revitalizado otros procesos de integración ya existentes, aunque ahora bajo la bandera del libre comercio (ALADI, MCCA, Caricom, Comunidad Andina), y se han firmado diferentes acuerdos comerciales, en su mayoría bilaterales o entre un país y un esquema de integración previo.

Así pues, en la región existen dos claros y diferenciados esquemas de integración comercial, el que representa NAFTA, centrado exclusivamente en la liberalización comercial, y el que representa Mercosur, que partiendo de la liberalización comercial aspira decididamente a convertirse en un proceso de auténtica integración regional. Mientras que tan sólo unos cuantos esquemas de integración comercial siguen el modelo del Mercosur (MCCA, Caricom y Comunidad Andina) el resto de los esquemas se basan en el modelo del NAFTA, poniendo de manifiesto el triunfo de la mera liberalización comercial frente a la integración regional.

La proliferación de acuerdos de libre comercio entre los diferentes países del hemisferio americano tiene una clara relación con el cambio de actitud en las relaciones entre Estados Unidos y América Latina. Muchos de los países latinoamericanos aspiran a tener un acuerdo de libre comercio con Estados Unidos, al igual que México, y esperanzados por la Iniciativa para las Américas, parecen estar interesados en demostrarle a su potencial socio su confianza en el libre comercio y su capacidad para llegar a acuerdos de este tipo con otros países de la región; de otra manera es difícil entender la proliferación de esquemas de integración en el hemisferio americano. Dichos 


\section{TABLA 1. Acuerdos de integración vigentes en las américas en los noventa}

\begin{tabular}{|c|c|c|}
\hline NOMBRE DEL ACUERDO & PAÍSES FIRMANTES & AÑO DE FIRMA \\
\hline $\begin{array}{l}\text { Mercado Común Centroamericano - } \\
\text { MCCA. }\end{array}$ & Costa Rica, El Salvador, Honduras, Guatemala y Nicaragua. & $\begin{array}{c}1960 \\
(1993)\end{array}$ \\
\hline Comunidad Andina (Pacto Andino). & Colombia, Bolivia, Perú, Ecuador y Venezuela. & 1969 (1996) \\
\hline Comunidad del Caribe - Caricom. & $\begin{array}{c}\text { Antigua y Barbuda, Bahamas, Barbados, Belice, Dominica, } \\
\text { Granada, Guyana, Haití, Jamaica, Montserrat, St. Kitts y } \\
\text { Nevis, Santa Lucía, San Vicente y las Granadinas y } \\
\text { Trinidad y Tobago. }\end{array}$ & 1973 \\
\hline $\begin{array}{l}\text { Asociación Latinoamericana de } \\
\text { Integración - ALADI (ALALC). }\end{array}$ & $\begin{array}{c}\text { Colombia, Venezuela, Ecuador, Bolivia, Perú, Brasil, Chile, } \\
\text { Argentina, Paraguay, Uruguay y México. }\end{array}$ & 1980 \\
\hline $\begin{array}{l}\text { Acuerdo de Libre Comercio entre } \\
\text { Chile y México. }\end{array}$ & Chile y México. & $\begin{array}{c}1991 \\
(1998)\end{array}$ \\
\hline Mercado Común del Sur - Mercosur. & Argentina, Brasil, Paraguay y Uruguay. & 1991 \\
\hline $\begin{array}{l}\text { Acuerdo de Libre Comercio entre } \\
\text { Caricom y Venezuela. }\end{array}$ & $\begin{array}{c}\text { Antigua y Barbuda, Bahamas, Barbados, Belice, Dominica, } \\
\text { Granada, Guyana, Haití, Jamaica, Montserrat, St. Kitts y } \\
\text { Nevis, Santa Lucía, San Vicente y las Granadinas, Trinidad } \\
\text { y Tobago, y Venezuela. }\end{array}$ & 1992 \\
\hline $\begin{array}{l}\text { Acuerdo de Norteamericano de } \\
\text { Libre Comercio - NAFTA. }\end{array}$ & Canadá, Estados Unidos y México. & 1992 \\
\hline $\begin{array}{l}\text { Acuerdo de Libre Comercio entre } \\
\text { Chile y Colombia. }\end{array}$ & Chile y Colombia. & 1993 \\
\hline $\begin{array}{l}\text { Acuerdo de Libre Comercio entre } \\
\text { Chile y Venezuela. }\end{array}$ & Chile y Venezuela. & 1993 \\
\hline $\begin{array}{l}\text { Acuerdo de Libre Comercio entre } \\
\text { Chile y Bolivia. }\end{array}$ & Chile y Bolivia. & 1993 \\
\hline $\begin{array}{c}\text { Grupo de los Tres. Acuerdo de libre } \\
\text { comercio. }\end{array}$ & Colombia, México y Venezuela. & 1994 \\
\hline $\begin{array}{l}\text { Acuerdo de Libre Comercio entre } \\
\text { Caricom y Colombia. }\end{array}$ & $\begin{array}{c}\text { Antigua y Barbuda, Bahamas, Barbados, Belice, Dominica, } \\
\text { Granada, Guyana, Haití, Jamaica, Montserrat, St. Kitts y } \\
\text { Nevis, Santa Lucía, San Vicente y las Granadinas, Trinidad } \\
\text { y Tobago, y Colombia. }\end{array}$ & 1994 \\
\hline $\begin{array}{l}\text { Acuerdo de Libre Comercio entre } \\
\text { México y Costa Rica. }\end{array}$ & México y Costa Rica. & 1994 \\
\hline $\begin{array}{l}\text { Acuerdo de Libre Comercio entre } \\
\text { México y Bolivia. }\end{array}$ & México y Bolivia. & 1994 \\
\hline $\begin{array}{l}\text { Acuerdo de Libre Comercio entre } \\
\text { Chile y Ecuador. }\end{array}$ & Chile y Ecuador. & 1994 \\
\hline $\begin{array}{l}\text { Acuerdo de Libre Comercio entre } \\
\text { Mercosur, Chile y Bolivia. }\end{array}$ & Argentina, Brasil, Paraguay, Uruguay, Chile y Bolivia. & 1996 \\
\hline $\begin{array}{l}\text { Acuerdo de Libre Comercio entre } \\
\text { Chile y Canadá. }\end{array}$ & Chile y Canadá. & 1996 \\
\hline $\begin{array}{l}\text { Acuerdo de Libre Comercio entre } \\
\text { México y Nicaragua. }\end{array}$ & México y Nicaragua. & 1997 \\
\hline $\begin{array}{l}\text { Acuerdo de Libre Comercio entre } \\
\text { Chile y Perú. }\end{array}$ & Chile y Perú. & 1998 \\
\hline $\begin{array}{l}\text { Acuerdo de libre comercio entre } \\
\text { MCCA y República Dominicana. }\end{array}$ & $\begin{array}{l}\text { Costa Rica, El Salvador, Honduras, Guatemala, Nicaragua y } \\
\text { República Dominicana. }\end{array}$ & 1998 \\
\hline $\begin{array}{l}\text { Acuerdo de Libre Comercio entre } \\
\text { Caricom y República Dominicana. }\end{array}$ & $\begin{array}{c}\text { Antigua y Barbuda, Bahamas, Barbados, Belice, Dominica, } \\
\text { Granada, Guyana,Haití, Jamaica, Montserrat, St. Kitts y } \\
\text { Nevis, Santa Lucía, San Vicente y las Granadinas, Trinidad } \\
\text { y Tobago, y República Dominicana. }\end{array}$ & 1998 \\
\hline $\begin{array}{l}\text { Acuerdo de Libre Comercio entre } \\
\text { Comunidad Andina y Brasil. }\end{array}$ & Colombia, Bolivia, Perú, Ecuador, Venezuela y Brasil. & 1999 \\
\hline
\end{tabular}

Fuente: BID (1999, p.46); entre paréntesis, año de reforma durante los noventa o nombre que recibía con anterioridad. 


\section{TABLA 2. Principales acuerdos en discusión}

\begin{tabular}{|l|l|}
\hline NOMBRE DEL ACUERDO & DIMENSIÓN \\
\hline Área de Libre Comercio de las Américas & Hemisférica \\
\hline Área de Libre Comercio entre Comunidad Andina y Panamá & Subregional \\
\hline Área de Libre Comercio entre MCCA y Chile & Subregional \\
\hline Área de Libre Comercio entre MCCA y Panamá & Subregional \\
\hline Área de Libre Comercio entre Chile y Panamá & Subregional \\
\hline Área de Libre Comercio entre México y Ecuador & Subregional \\
\hline Área de Libre Comercio entre México, El Salvador, Nicaragua y Honduras & Subregional \\
\hline Área de Libre Comercio entre México y Panamá & Subregional \\
\hline Área de Libre Comercio entre México y Perú & Subregional \\
\hline Área de Libre Comercio entre Mercosur y Unión Europea & Extraregional \\
\hline Área de Libre Comercio entre México y Unión Europea & Extraregional \\
\hline Área de Libre Comercio entre Chile y Unión Europea & Extraregional \\
\hline Área de Libre Comercio entre Caricom y Unión Europea & Extraregional \\
\hline Área de Libre Comercio entre Chile y Corea del Sur & Extraregional \\
\hline Foro de Cooperación Económica del Asia-Pacífico - APEC & Extraregional \\
\hline
\end{tabular}

Fuente: BID (1999, p. 46).

esquemas aparecen reflejados en la Tabla 1, mientras que otros procesos de integración subregionales y extrarregionales aún en discusión aparecen en la Tabla 2.

Algunos de estos esquemas de integración tienen tal entidad que consideramos necesario dedicarles unas líneas.

\section{a) NAFTA}

En el Acuerdo de Libre Comercio de Norteamérica (NAFTA o TLC) participan Estados Unidos, Canadá y México, y surgió en 1994 tras la adhesión de México al tratado de libre comercio establecido en 1989 entre Canadá y Estados Unidos. El NAFTA agrupa a 384,5 millones de habitantes, en una superficie de 21,3 millones de $\mathrm{km}^{2}$, y genera 7,8 billones de dólares de PIB. Lo más novedoso de este acuerdo de integración regional, y que marca un cambio en el modelo de integración, es el hecho de que lo forman dos países 
desarrollados y uno subdesarrollado; hasta este acuerdo los modelos de integración partían del supuesto de que los países debían tener similares niveles de desarrollo. Esto puede deberse al hecho de que no tiene vocación de ser más que una zona de libre mercado, por lo que no es necesaria una homogeneidad previa a la integración.

EI NAFTA pretende liberalizar la relaciones económicas entre los países miembros, permitiendo en no más de 15 años la libre circulación de capitales, bienes y servicios; y para ello se han establecido reducciones mutuas y progresivas de las barreras arancelarias y no arancelarias, y de las limitaciones impuestas a las inversiones extranjeras. Los intereses de México en el NAFTA son las inversiones norteamericanas que puede obtener, mientras que Canadá y Estados Unidos, sobre todo éste, se aseguran la reserva de un importante mercado, al tiempo que generan empleo en las zonas de donde procede gran parte de la inmigración que reciben.

\section{b) MCCA}

El Mercado Común Centroamericano (MCCA o Mercomún) es un acuerdo de integración regional constituido por Guatemala, Nicaragua, El Salvador, Costa Rica y Honduras. El MCCA agrupa a 31,6 millones de habitantes, en una superficie de $423 \mathrm{mil} \mathrm{km}$, y genera un PIB de 33.100 millones de dólares. Dicho acuerdo nació en 1960 como una zona de libre comercio con vocación de convertirse en un mercado común. Aunque sólo logró ser una unión aduanera, con un arancel exterior común y una reducción de los aranceles internos, sí ha tenido un importante desarrollo institucional y su vocación integradora ha sido clara.

Los primeros resultados del acuerdo fueron muy positivos, pasando de un comercio intra-regional de 36 millones de dólares en 1960 a los 1.000 millones en 1980. Sin embargo, la crisis política y económica que atravesó Centroamérica durante los años ochenta, paralizó este acuerdo y redujo significativamente los intercambios; pero en los noventa la situación cambió. El Protocolo de Guatemala de 1993 parece haber revitalizado este acuerdo, aunque bajo un marco mucho más flexible, de forma que la aplicación de políticas de liberalización comercial en casi todos los países, la reforma y posterior no aplicación generalizada del arancel exterior común y la continua invocación de cláusulas de salvaguardia, han hecho que en la actualidad el MCCA funcione más como un área de libre comercio 
que como una unión aduanera; de hecho tan sólo Guatemala y El Salvador aspiran hoy a constituir una unión aduanera.

\section{c) Caricom}

La Comunidad del Caribe (Caricom) se constituyó en 1973 como un paso más en el proceso de integración del Área de Libre Comercio del Caribe (CARIFTA); constituyen la Caricom las islas caribeñas de Antigua y Barbuda, Bahamas, Barbados, Dominica, Granada, Haití, J amaica, Montserrat, St. Kitts y Nevis, Santa Lucía, San Vicente y las Granadinas, Trinidad y Tobago y los territorios continentales de Guyana y Belice. Todos estos territorios, salvo Bahamas y Haití, constituyen además el Mercado Común del Caribe, por lo que la Comunidad y el Mercado suelen identificarse igualmente como Caricom. La Caricom, como Comunidad, agrupa a una población cercana a los 6 millones de habitantes, en una superficie de poco más de 147 mil km² y genera un PIB de 16.900 millones de dólares de 1990.

Tal vez lo más relevante de este acuerdo de integración sea, por un lado, la flexibilidad del tratado (diferentes ritmos de aplicación de las cláusulas, integraciones parciales más intensas, moneda común en parte de la región...) y, por otro, la separación física entre los países, porque el intercambio intraregional es muy escaso (el máximo intercambio histórico fue de 380 millones de dólares en 1982) y la mayor parte de las relaciones comerciales de cada país son con Estados Unidos; esto último se debe a que la Iniciativa para la Cuenca de Caribe ha favorecido las relaciones comerciales con este país. Este acuerdo, además de contar con un arancel exterior común y un desarme arancelario intra-regional, ha tenido un importante desarrollo institucional (sistema de crédito y seguro común, banco central y moneda común en parte del territorio, armonización fiscal, cooperación y homogeneización funcional en educación, salud, deportes, cultura, medio ambiente, derechos civiles, asentamientos humanos, relaciones exteriores...).

Sin embargo, los años ochenta supusieron también un retroceso en el proceso de integración; el comercio intra-regional se contrajo en un $63 \%$ y el sistema de compensación de pagos dejó de funcionar por problemas de endeudamiento. A comienzos de los noventa, de nuevo se retomaron los esfuerzos por revitalizar la Caricom (reforma del arancel exterior común, aceleración del desarme arancelario interno, restablecimiento del sistema decompensación de pagos, mayor armonización legislativa, librecirculación 
de personas, incentivos al desarrollo de un sistema intra-regional de transportes, preparación de una moneda común...).

\section{d) ALADI}

La Asociación Latinoamericana de Integración (ALADI) surgió en 1980 como transformación de la Asociación Latinoamericana de Libre Comercio (ALALC) y está formada por todos los países latinoamericanos de América del Sur (Colombia, Venezuela, Ecuador, Bolivia, Perú, Brasil, Chile, Argentina, Paraguay y Uruguay) y México. Esta asociación se creó con el objeto de ir más allá de la conformación de una zona de libre comercio, paraconformar a largo plazo un mercado común latinoamericano.

Se trata de un proceso de integración flexible, en el que existe una preferencia arancelaria regional y la posibilidad de firmar acuerdos parciales en los que sólo participan algunos de sus miembros (Comunidad Andina, Mercosur, Grupo de los Tres...). A lo único que obliga la ALADI es a regular el comercio recíproco y a desarrollar acciones para la cooperación de mercado.

Este acuerdo se ha revitalizado también desde principios de los noventa y de él destacan su flexibilidad y el número de países que lo forman; sin embargo, los avances en materia de integración general son bastante modestos.

\section{e) Comunidad Andina}

El Acuerdo de Cartagena o Pacto Andino es un proceso de integración regional firmado en 1969 por Colombia, Bolivia, Ecuador, Perú y Chile; este último se retiró en 1976, mientras que Venezuela se incorporó en 1973. El Pacto Andino agrupa a 109 millones de habitantes, en una superficie de 4,7 millones de $\mathrm{km}^{2}$ y genera un PIB de 216.000 millones de dólares de 1990. Se trata de un acuerdo de integración con pretensiones de instaurar un mercado común, pero que en su desarrollo no consiguió siquiera la implantación generalizada de un arancel exterior común, y tuvo que enfrentar importantes problemas de heterogeneidad de sus miembros, con tratamientos diferenciados. A finales de los setenta el Pacto Andino sufrió una importante crisis política a la que se sumó la crisis económica de los ochenta, que contrajo los intercambios intra-regionales a cifras inferiores al $4 \%$; a pesar de todo ello, 
el desarrollo institucional continuó durante los ochenta.

A principios de los noventa se revitaliza el Pacto Andino, cambiando incluso su nombre a Comunidad Andina, conformándose una unión aduanera entre Colombia, Ecuador y Venezuela y una zona de libre comercio entre éstos y Bolivia. Perú se distanció mucho del desarrollo del proceso, firmando sólo acuerdos bilaterales de libre comercio con sus socios, aunque en 1997 acordó integrarse plenamente en el área de libre comercio antes del 2005.

\section{f) Mercosur}

El Mercado Común del Sur (Mercosur) surgió en 1991 cuando Paraguay y Uruguay decidieron participar del proceso de integración iniciado por Brasil y Argentina a mediados de los ochenta. El Mercosur agrupa a 210,5 millones de habitantes, en una superficie de 11,9 millones de $\mathrm{km}^{2}$ y genera un PIB de 792.900 millones de dólares de 1990.

El Mercosur es más que una zona de libre comercio y, a pesar de su flexible institucionalidad, puede considerarse el proceso de integración más avanzado e importante de las Américas. La unión aduanera es un hecho; posee un arancel exterior común, hay una liberalización comercial intra-regional importante y existe una coordinación de las políticas macroeconómicas, sectoriales y exteriores, así como una armonización legislativa. El desarrollo del comercio intra-regional se multiplicó por cinco entre 1990 y 1997, pasando de 4.000 millones de dólares a 21.000 millones, aunque la crisis financiera que afectó a Brasil en 1998 ha frenado la expansión de dicho comercio; aun así, se está configurando como el segundo proceso de integración del mundo tras la Unión Europea.

El ALCA, por ser el esquema de integración más ambicioso (por su extensión, que no por su intensidad), por ser el único que incluye a países desarrollados y subdesarrollados ( sin contar el NAFTA, pues en cierto modo el ALCA es una extensión de éste) y por ser un marco de referencia de las relaciones entre Estados Unidos y América Latina para el siglo XXI, merece sin duda que le dediquemos una especial atención. 


\section{EL ÁREA DE LIBRE COMERCIO DE LAS AMÉRICAS}

La Iniciativa para las Américas del Presidente Bush tomó forma real bajo la Administración Clinton. Por iniciativa norteamericana se reunieron en Miami en 1994 los gobernantes de 34 de los 35 países americanos (a excepción de Cuba) con el objeto de sentar las bases para configurar el Área de Libre Comercio de las Américas (ALCA), que debería abarcar desde Alaska hasta la Patagonia y unificaría así las economías del hemisferio americano. A través de una Declaración de Principios y un Plan de Acción quedó el compromiso de avanzar substancialmente en las siguientes rondas negociadoras, que habrían de concluir en el año 2005 con la firma de un acuerdo hemisférico.

\subsection{La institucionalización del ALCA}

En la Cumbre de Miami de 1994 (I Cumbre de las Américas), los mandatarios de los países del hemisferio establecieron como objetivos la creación de la zona de libre comercio más grande del mundo, el fortalecimiento de la democracia de sus países y la protección de los derechos humanos, la lucha contra la corrupción y el narcotráfico y el acceso universal a la educación.

Así mismo, a raíz de dicha cumbre se inició un proceso de reuniones periódicas de los 34 Ministros de Comercio de cara a preparar las negociaciones para la integración hemisférica. En dichas Reuniones Ministeriales de Comercio (Denver, EE.UU., 1995; Cartagena, Colombia, 1996; Belo Horizonte, Brasil, 1997; San J osé, Costa Rica, 1998) debían desarrollarse los cuatro ejes del Plan de Acción acordado, que son la preservación y el fortalecimiento de la comunidad de democracias de las Américas, la promoción de la prosperidad mediante la integración económica y el libre comercio, la erradicación de la pobreza y la discriminación en el hemisferio y la garantía del desarrollo sostenible y la conservación del medio ambiente para las generaciones futuras. Sin embargo, en esas cuatro rondas todo el debate se centró en la liberalización comercial; Ios otros tres ejes fueron postergados, lo que pone de manifiesto el carácter neoliberal del acuerdo, centrado en el libre comercio a pesar de la declaración de intenciones.

Sin embargo, en 1998 tuvo lugar la Cumbre de Santiago (II Cumbre de las Américas), donde se produjo un significativo impulso al proceso de conformación del área, abriéndose las puertas a la negociación, y donde se decidió dar mayor importancia a los objetivos más descuidados hasta la fecha. Dado 
que se han producido ya progresos importantes en materia de libre comercio e integración económica de cara al 2005, se pretende ahora priorizar en la agenda la educación de cara al 2010, de forma que los países de la región apliquen nuevas estrategias encaminadas a la plena alfabetización y la mejora en la calidad de la educación ( $100 \%$ de escolarización primaria, $75 \%$ de escolarización secundaria, mayor permanencia); para ello el Banco Mundial, el BID y la Agencia para el Desarrollo Internacional de Estados Unidos aportarán un total de 8.320 millones de dólares entre 1998 y 2010. Los demás objetivos también se han visto reforzados financieramente, tal es el caso del fortalecimiento de la democracia y la protección de los derechos humanos (5.380 millones), la lucha contra la corrupción y el narcotráfico (12.530 millones) y la integración económica y el libre comercio ( 18.870 millones). El hecho de que existan objetivos diferentes del libre comercio y de que éstos sean apoyados financieramente, no significa que el ALCA sea realmente un proceso de integración, tan sólo que se trata de un esquema de integración basado en el libre comercio donde existe una cierta preocupación por los aspectos sociales y políticos, al menos de cara a la opinión pública.

Tras la Cumbre de Santiago, a finales de 1999 tuvo lugar la Quinta Reunión Ministerial de Comercio en Toronto, Canadá, en la que comenzaron las negociaciones encargándose a los diferentes Grupos de Trabajo, ahora convertidos en Grupos de Negociación, el desarrollo de las mismas.

El esfuerzo para crear el ALCA, como proceso dinámico, se apoya en tres elementos: Ios Ministros de Comercio, que han desarrollado el plan de trabajo completo para el ALCA; los Viceministros de Comercio, que conforman el Comité de Negociaciones Comerciales, coordinan los esfuerzos de los Grupos de Negociación y dan recomendaciones a los Ministros de Comercio sobre las políticas a seguir; y los Grupos de Negociación Hemisféricos, establecidos por los Ministros de Comercio, encargados de las negociaciones por cada materia, y que fueron constituidos a partir de los Grupos de Trabajo, cuya misión hasta la Cumbre de Santiago consistió en recolectar y compilar información sobre el estado de las relaciones comerciales en el hemisferio.

En cuanto a los Grupos de Negociación, procedentes de los Grupos de Trabajos previos, éstos se encuentran organizados en nueve áreas temáticas, a saber: acceso a mercados; inversiones; servicios; compras del sector público; solución de diferencias; agricultura; derechos de propiedad intelectual; subsidios, antidumping y derechos compensatorios; y 
política de competencia. Los Grupos de Trabajo de procedimientos aduanero y reglas de origen y de normas y barreras técnicas se disolvieron una vez que compilaron toda la información sobre dichos temas. El Grupo de Trabajo sobre Economías Pequeñas se ha convertido en el Grupo Consultivo sobre Economías más Pequeñas, un órgano abierto a la participación de todos los países del ALCA, encargado de elevar a la consideración del Comité de Negociaciones Comerciales aquellos asuntos que sean de interés para las economías más pequeñas.

Además de estas reuniones entre políticos y técnicos, el ALCA ha incluido la participación de algunos elementos de la sociedad civil de los distintos países por medio de reuniones conocidas como Foros Empresariales que se han reunido cuatro veces antes de la Cumbre de Santiago; éstos buscan la inclusión del sector privado como participante activo en la construcción de este mercado regional, teniendo en cuenta que el dinamismo productivo de un país, así como la generación de empleo, están en gran medida dados por este sector. A través del mecanismo de la Red Empresarial para la Integración Hemisférica, los principales actores de las comunidades empresariales de los países y regiones del hemisferio han intercambiado activamente información y han dialogado con ese objetivo. Sin embargo, a raíz de la Cumbre de Santiago se creó el Comité de Representantes Gubernamentales sobre la Participación de la Sociedad Civil, como forma de dar cabida a la sociedad civil (comunidad empresarial, organizaciones laborales y de medio ambiente, grupos académicos...) en las negociaciones. En dicha Cumbre también se creó el Comité Conjunto de Expertos del Gobierno y del Sector Privado sobre Comercio Electrónico, un claro ejemplo de la importancia otorgada a la llamada nueva economía en este esquema de integración; no en vano Estados Unidos es el líder mundial en el sector de las nuevas tecnologías de la información y las telecomunicaciones.

Llama la atención que los Grupos de Negociación se dediquen sólo a cuestiones relacionadas con el libre comercio, mientras quetodo lo referente al resto de los objetivos del ALCA carezca de un marco institucional de desarrollo. Queda la esperanza de que el Comité de Representantes Gubernamentales sobre la Participación de la Sociedad Civil impulse las discusiones sobre estos otros aspectos, pero aun así está claro que lo que interesa a los mandatarios americanos es el libre comercio.

En plano administrativo, se ha creado una Secretaría Administrativa con sede en Miami y un Subcomité del Comité de Negociaciones Comerciales 
sobre Presupuesto y Administración, mientras que en lo que respecta al apoyo logístico, existe un Comité Tripartito compuesto por la Organización de Estados Americanos (OEA), el Banco Interamericano de Desarrollo (BID) y la Comisión Económica para América Latina (CEPAL), quienes proporcionan asistencia técnica al proceso. Además, a petición específica de los Grupos de Trabajo, expertos pertenecientes a estas instituciones han desarrollado compendios y bases de datos sobre diversos asuntos de política comercial. A pesar de estos elementos el ALCA es un esquema de integración carente de supranacionalidad, es decir, no pretende conformarse en un organismo internacional con personalidad jurídica propia, como lo puede ser, por ejemplo, la Unión Europea; este hecho supone que los países firmantes del acuerdo no cederán soberanía a ningún ente superior y tan sólo se comprometerán a cumplir los firmado. A pesar de que los acuerdos se toman por consenso y las conclusiones de la negociación constituirán un compromiso único comprensivo, la falta de supranacionalidad también puede favorecer que los países más fuertes incumplan dichos acuerdos sin que ningún organismo tenga capacidad coercitiva sobre ellos y, como en el caso de otros tratados, el derecho internacional sólo sea aplicable a los países más débiles.

Así las cosas, el ALCA abarcará los 34 países miembros de la OEA, no se constituirá a través de la expansión de ningún grupo único y no tiene ningún propósito definido más allá de un acuerdo de libre comercio, debiendo ser compatible con los acuerdos subregionales existentes, que pueden seguir fortaleciéndose, y de hecho lo hacen, mientras negocian el ALCA; de esta forma, los países pueden negociar en forma individual o por grupos (tanto Mercosur como el Caricom así lo hacen, mientras los miembros del NAFTA negocian individualmente). Los alcances del ALCA son los de un acuerdo de libre comercio «moderno», ya que abarcará temas como inversión, competencia, propiedad intelectual y comercio de servicios, siendo todo congruente con la OMC, aunque ello suponga desperdiciar la oportunidad de abarcar temas propios de los procesos de integración "tradicionales", como libre circulación de trabajadores, tarifa exterior común, homogeneización de los marcos regulatorios internos, reducción de las disparidades regionales, políticas comunes, moneda común... 


\subsection{Valoración cuantitativa del ALCA}

La definitiva constitución del ALCA en el 2005 supondrá la conformación de un bloque comercial que, con datos de 1998, englobaría a más de 791 millones de habitantes, en unos 51,3 millones de $\mathrm{km}^{2}$, generando más de 9 billones de dólares de PIB y exportando productos por valor de unos 1,2 billones de dólares, lo que representa más del $13 \%$ de la población mundial, el $38,4 \%$ del territorio del planeta, el $33 \%$ de la producción mundial y más del $11 \%$ de las exportaciones mundiales. De configurarse, el ALCA será sin duda el bloque comercial más importante del mundo.

Pero si nos detenemos a ver las cifras del comercio intra-regional podemos apreciar la heterogeneidad, como cabría esperar, de este bloque. Lo primero que puede apreciarse en la Tabla 3, es que el comercio intra-regional del ALCA representaría, con datos de 1999, tan sólo el 59,1\% de las exportaciones del hemisferio, cantidad que, a pesar de no ser muy elevada, presenta una tendencia a aumentar y es superior a la que representaba el comercio intra-regional de la hoy Unión Europea tras la firma del Tratado de Roma.

\section{TABLA 3. Exportaciones de los países de Alca, Nafta y América Latina según destino (1999)}

\begin{tabular}{|l|c|c|c|c|c|c|c|c|}
\hline & ALCA & NAFTA & $\begin{array}{c}\text { EE.Uu. } \\
\text { y Canadá }\end{array}$ & $\begin{array}{c}\text { América } \\
\text { Latinay } \\
\text { Caribe }\end{array}$ & $\begin{array}{c}\text { América } \\
\text { Latina }\end{array}$ & $\begin{array}{c}\text { América } \\
\text { Latina y } \\
\text { Caribe sin } \\
\text { México }\end{array}$ & $\begin{array}{c}\text { América } \\
\text { Latina sin } \\
\text { México }\end{array}$ & Mundo \\
\hline ALCA & 59,1 & 51,2 & 44,4 & 15,2 & 14,7 & 8,4 & 7,9 & 100 \\
\hline NAFTA & 59,3 & 53,7 & 46,0 & 13,7 & 13,3 & 6,0 & 5,6 & 100 \\
\hline Amér. Latina & 74,4 & 60,5 & 60,0 & 15,1 & 14,4 & 14,6 & 13,9 & 100 \\
\hline
\end{tabular}

Fuente: Elaboración propia a partir de datos del BID (1997); datos en porcentajes del total de las exportaciones de cada grupo.

En segundo lugar, destaca que dentro del ALCA el principal mercado es el NAFTA que recibe el $51,2 \%$ de las exportaciones del hemisferio, con tendencia a aumentar, y el 60,5\% de las de América Latina, con igual tendencia; pero si descontamos las exportaciones dirigidas hacia México, los dos países desarrollados del ALCA recibirían el 44,4\% de las exportaciones hemisféricas y el $60 \%$ de las exportaciones de América Latina, ambas cantidades con igual tendencia al aumento. Todo esto justifica el gran interés que han demostrado los países latinoamericanos en la conformación del ALCA, ya que les permi- 
tiría acceder libremente a los dos mercados más importantes del hemisferio. El estímulo y la estabilidad que le darían al sector exterior de los países latinoamericanos ha hecho que muchos de ellos tengan depositadas grandes esperanzas en que el ALCA sirva para generar un crecimiento económico que les permita avanzar en la senda del desarrollo.

No obstante, no todos los países latinoamericanos tienen el mismo interés por la conformación del ALCA. Como se aprecia en la Tabla 4, el G3 (Colombia, México y Venezuela) tienen una gran dependencia de los mercados del ALCA ( $90 \%$ de sus exportaciones, con tendencia a aumentar) y sobre todo del NAFTA ( $82,8 \%$, con igual tendencia), mientras que Mercosur tiene más diversificado el destino de sus exportaciones, dirigiendo hacia el ALCA tan sólo el $48,7 \%$ de ellas, aunque con tendencia al aumento, repartidas de forma que el $20,7 \%$ van hacia el NAFTA, con igual tendencia, y el $19,9 \%$ es comercio intra-regional de Mercosur, cifra esta que se eleva al $24,2 \%$ en el caso del acuerdo de libre comercio entre el Mercosur, Chile y Bolivia, ambas cantidades con tendencia a disminuir. Para otros esquemas de integración como la Comunidad Andina o el MCCA, el ALCA viene a representar el destino de más del $70 \%$ de sus exportaciones, con tendencia a aumentar.

\section{TABLA 4. Exportaciones desde los distintos esquemas de integración según destino (1999)}

\begin{tabular}{|l|r|r|r|r|r|r|r|r|r|r|}
\hline & ALCA & NAFTA & MERCOSUR & MCCA & CARRCOM & $\begin{array}{r}\text { Conun. } \\
\text { Andina }\end{array}$ & G-3 & $\begin{array}{r}\text { MERCOSOR } \\
\text { ChileBdivia }\end{array}$ & ALADI & Mundo \\
\hline ALCA & 59,1 & 51,2 & 3,2 & 1,2 & 0,5 & 1,7 & 8,5 & 3,8 & 12,8 & 100 \\
\hline NAFTA & 59,3 & 53,7 & 2,0 & 1,0 & 0,4 & 1,3 & 9,0 & 2,3 & 11,6 & 100 \\
\hline MERCO SUR & 48,7 & 20,7 & 19,9 & 0,5 & 0,2 & 3,5 & 3,1 & 24,2 & 28,2 & 100 \\
\hline MCCA & 75,6 & 53,3 & 0,1 & 20,3 & 0,7 & 0,7 & 2,5 & 0,4 & 3,3 & 100 \\
\hline Comun. Andina & 71,3 & 47,9 & 2,9 & 2,7 & 3,7 & 8,8 & 6,9 & 5,2 & 15,2 & 100 \\
\hline G-3 & 90,0 & 82,8 & 0,9 & 1,3 & 1,0 & 2,3 & 1,7 & 1,3 & 3,8 & 100 \\
\hline ALADI & 74,3 & 60,8 & 6,7 & 1,0 & 0,7 & 3,1 & 2,6 & 8,5 & 12,1 & 100 \\
\hline
\end{tabular}

Fuente: BID (1997); datos en porcentajes del total de las exportaciones de cada grupo.

Todo esto, junto con la diferente naturaleza de Mercosur, que va más allá del libre comercio y aspira a convertirse en un auténtico mercado común, explicaría las reticencias de Brasil, como líder de Mercosur, ante el ALCA; la 
primera batalla ganada por Mercosur en el seno de la conformación del ALCA ha sido la posibilidad de negociar como bloque regional, lo que hace suponer que este esquema de integración hará valer su peso económico en las negociaciones, no tanto para obtener un fácil acceso al mercado norteamericano, como para evitar que la competencia de los productos de sus vecinos dañe sus industrias.

Por otro lado, entre los países más favorables al acuerdo se encontraría Chile que lleva varios años querien do formar parte del NAFTA y cuyo ingreso está bloqueado en el Congreso de Estados Unidos, a pesar de tener firmados ya acuerdos de libre comercio con Canadá y México. Otro tanto puede decirse de los países del MCCA y de Caricom, que tienen acuerdos de libre comercio con México y con los otros dos miembros del G-3.

Por su parte los países del NAFTA, que destinan el 59,3\% de sus exportaciones al ALCA, con tendencia a aumentar, las dirigen esencialmente al comercio intra-regional, que representa $53,7 \%$, de los que 46 puntos van a los mercados de Estados Unidos y Canadá, ambas cantidades con tendencia a aumentar; el NAFTA sólo destina al resto del ALCA el $6 \%$ de sus exportaciones, con tendencia a disminuir. Esto explicaría el escaso interés mostrado por Estados Unidos en avanzar en las negociaciones por la vía rápida (fast track), ya que para este país la región tiene un valor más estratégico que comercial; esto es debido a que en la lógica de la geopolítica del siglo XXI a Estados Unidos le resulta muy útil tener un importante mercado potencial abierto a sus productos en el caso de producirse una guerra comercial.

En esta misma lógica, Estados Unidos ha propuesto también a los países asiáticos del Foro de Cooperación Económica Asia-Pacífico (APEC) y a los países del África Negra la formación de dos nuevas zonas de libre comercio, en un claro intento por evitar que estos mercados caigan en manos exclusivas de la Unión Europea o de Japón. Sin embargo, a América Latina, el tener que compartir las ventajas comerciales adquiridas en el seno del ALCA con países de otras zonas, puede que no le resulte tan interesante; aunque siempre tiene la posibilidad de negociar acuerdos comerciales similares con la Unión Europea o J apón. De hecho la Cumbre Euro-Latinoamericana de Río en 1999 ha supuesto un importante impulso en este sentido, habiéndose iniciado negociaciones entre la Unión Europea y Mercosur, Chile y México; otro tanto puede decirse de la participación de países latinoamericanos en APEC. De producirse esta expansión extrarregional de los acuerdos de libre comercio, los posicionamientos geopolíticos conducirían a una extensión 
del libre cambio más intensa que la que ampara la OMC (para satisfacción de los economistas neoliberales).

\subsection{Valoración cualitativa del ALCA}

Cuando se trata de entrar a valorar los aspectos cualitativos de este proceso de integración, una de las primeras consideraciones que podemos hacer es el carácter imperialista o panamericanista del mismo, atendiendo a una nomenclatura propia de la Guerra Fría pero que consideramos sigue teniendo validez. Aunque no faltan autores que ven en el ALCA una aplicación más de la Doctrina Monroe, por cuanto Estados Unidos trata de impedir que otras potencias económicas adquieran hegemonía en la región, la actitud que este país está manteniendo en las negociaciones, así como las concesiones que ya hiciera bajo la Iniciativa para las Américas, parecen más propias de un enfoque panamericanista que de una postura imperialista; de hecho el mayor interés en el proyecto proviene de los países latinoamericanos. No obstante, al ser Estados Unidos el centro hegemónico del área, éste ha hecho valer su peso en las negociaciones marcando la orientación de la mismas y localizando la Secretaría Administrativa en Miami.

Una segunda cuestión relevante es el alcance del ALCA como proyecto de integración. En este sentido hay que decir que, siendo estrictos, no se trata de un proceso de integración, sino tan sólo de un único paso de liberalización comercial regional. Y esto es así porque, siguiendo el modelo del NAFTA, en ningún momento se está planteando la conformación a largo o medio plazo de una unión política, monetaria o económica, ni siquiera de un mercado común; es decir, no hay interés por integrarse, tan sólo por liberalizar. El ALCA, por tanto, no tendrá un carácter supranacional, como lo puede tener la Unión Europea, tan sólo será un acuerdo multilateral donde las decisiones se tomarán por consenso.

Es precisamente esta falta de la supranacionalidad, que se transforma en la falta de un organismo regulador del mercado hemisférico, lo que pone una vez más de manifiesto el carácter neoliberal del proceso. Con el ALCA se está creando un mercado que supera las competencias reguladoras de los Estados de los diferentes países, un mercado sobre el que no cabela intervención ni de los gobiernos nacionales, ni de un gobierno hemisférico inexistente. El espacio económico hemisférico se convierte así en un espacio de libre mercado. 
Al mismo tiempo el ALCA es un proyecto capaz de compatibilizar el multilateralismo con el regionalismo y los procesos de integración más avanzados a nivel subregional. Este acuerdo asume como mínimos los compromisos adquiridos en la Ronda Uruguay del GATT y, por tanto, su desarrollo es perfectamente compatible con los postulados de la OMC; a partir de aquí, los países del ALCA se otorgarán mutuamente ventajas comerciales que mejoren lo ya obtenido a través de la OMC. Por su parte, los acuerdos subregionales tomarán como mínimos lo que se acuerde en el ALCA, de forma tal que el grado de liberalismo será cada vez mayor a medida que nos acercamos de lo mundial (OMC), a lo hemisférico (ALCA), a lo subregional (NAFTA, Mercosur, G-3, MCCA...) y a lo nacional. El ALCA recoge, por tanto, los principios inspiradores del Regionalismo Abierto de la CEPAL.

Algunos autores criticaron que esta negociación se estaba llevando a cabo sin contar con la participación de la sociedad civil de los países implicados. Dado que el acuerdo implica importantes concesiones en materia comercial y la adopción de un modelo de desarrollo basado en la liberalización económica (modelo neoliberal), parece que no sólo los políticos de estos países debieran tener algo que decir; a pesar de ello, tal vez sea éste uno de los pocos procesos de integración donde algunos elementos de la sociedad civil, los empresarios, han tenido desde un primer momento una importante participación, aunque ello no es óbice para que se hubiese incluido desde el principio en el esquema a los sindicatos o a otras organizaciones no gubernamentales. Este aspecto se ha corregido con el Comité de Representantes Gubernamentales sobre la Participación de la Sociedad Civil.

Por último, lo más novedoso de este proceso de integración es que incluye a países de diferentes niveles de desarrollo. Hasta ahora se había considerado que para el éxito de un proceso de integración se requería de una homogeneización previa de los países que desean formar parte del mismo, por lo que los principales acuerdos se han hecho entre países relativamente homogéneos. Las diferencias estructurales que separan a Estados Unidos de Haití son tan abismales que en principio resulta difícil imaginar a esos dos países dentro del mismo esquema de integración; pero recordemos que se trata sólo de libre comercio, no habrá, por ejemplo, movilidad del factor trabajo, ni una moneda única, ni políticas comunes. Para comerciar no hace falta ser iguales, ni siquiera parecidos, es más, según la teoría ortodoxa del comercio internacional, cuanto más diferentes sean las estructuras productivas, mayores ventajas comparativas existirán y mayor podrá ser la especialización; dehecho uno de los problemas que tuvieron los anteriores procesos 
de integración en América Latina fue la ausencia de complementariedad entre sus producciones ya que los distintos países generaban los mismos productos u otros sustitutivos. En este caso, la existencia de un norte, eminentemente industrial, con producciones intensivas en factor capital, tecnología y conocimiento, y un sur, eminentemente primario-exportador, con producciones intensivas en recursos naturales y mano de obra barata, puede generar una importante complementariedad de las producciones que redunde en beneficio de todos los socios.

Sin embargo, como ya demostrara Raúl Prebisch hace medio siglo, existe una tendencia al deterioro de los términos de intercambio para los países que se especializan en la producción de bienes primarios (a excepción de recursos estratégicos muy escasos, como es el caso del petróleo); esta tendencia puede hoy día aplicarse igualmente a los países que se especializan en producciones intensivas en factor trabajo. Esta relación asimétrica termina por perjudicar a los países primario-exportadores, beneficiando a los industriales, salvo que, como en el caso de la Unión Europea, se adopten medidas compensatorias por vía financiera, en forma de transferencias al estilo de los Fondos FEDER, FEOGA (Orientación y Garantía), Fondo Social Europeo, Fondos de Cohesión, etc. Por el momento, los recursos que está previsto sean destinados por ALCA para el logro de sus objetivos no parece que sean suficientes, ni que vayan en la línea de asumir la compensación de las desigualdades.

Lo cierto es que la conformación del ALCA tal y como viene desarrollándose supone el triunfo del libre comercio sobre la integración económica, el triunfo de la opción más beneficiosa para Estados Unidos sobre la más beneficiosa para América Latina. Con el ALCA, Estados Unidos se reserva preferentemente el mercado latinoamericano y conserva su soberanía en materia económica, mientras que en un auténtico esquema de integración éstos se verían obligados, por ejemplo, a financiar la corrección de los desequilibrios territoriales o a aceptar inmigrantes latinoamericanos como consecuencia de la libre circulación de personas, y esto es al go que está fuera de toda posibilidad política. Los países latinoamericanos saldrían más beneficiados con un esquema de integración que con un simple acuerdo de libre comercio, pero aun así, y con la excepción quizá de los países de Mercosur, parecen haber dado por bueno el proyecto del ALCA, y auque éstos pueden avanzar en la conformación de esquemas de integración subregionales, parecen más interesados por firmar acuerdos de libre comercio entre ellos que en reforzar, por ejemplo, un esquema de integración como 
Mercosur. A falta de poder llegar a un acuerdo de libre comercio con Estados Unidos de momento, pareciera como si los países latinoamericanos se afanasen en demostrarles a aquél su capacidad para ello.

\subsection{Perspectivas de futuro}

Predecir el futuro es siempre una tarea difícil y arriesgada; si se trata de un futuro político la dificultad y el riesgo aumentan, pero si además nos estamos refiriendo al volátil escenario de las relaciones internacionales en el tránsito al nuevo milenio, la incertidumbre es demasiado grande, por lo que nos limitaremos a apuntar distintas posibilidades, obstáculos e impulsos.

La teoría de los husos geográficos ha sido frecuentemente utilizada para tratar de prever los escenarios futuros de las relaciones internacionales; bajo esta teoría la regionalización del planeta sería una de las características del próximo siglo y, de ser así, el ALCA sería una de esas grandes regiones. Según esta teoría el mundo quedaría dividido en tres grandes bloques; el europeo, con la Unión Europea como centro y una periferia formada por los países europeos en transición desde el socialismo y los países del norte de África, de Oriente Medio y del África subsahariana; el asiático, con Japón como centro y una periferia formada por China, el subcontinente indio y los países del Pacífico no americano; y el americano, con Estados Unidos como centro y una periferia formada por toda América Latina y los territorios caribeños de habla no hispana. De todos estos bloques es este último el que se encuentra más perfilado en el proyecto del ALCA, ya en ejecución.

Pero, frente a esta teoría, la imparable marcha de la globalización va imponiendo un universo de libre cambio mundial, que no entiende de fronteras ni nacionales ni regionales; los intereses de los agentes y empresas transnacionales no tienen por qué coincidir con los de las grandes potencias internacionales, y aquellos parecen apostar por la globalización frente a la regionalización que defienden los gobiernos. Si la globalización sigue su aparente imparable marcha, el ALCA podría convertirse en la ALADI del siglo $X X I$, es decir, en un esquema de integración nominal con escasa importancia real.

Con independencia de estos dos escenarios, en el propio proceso de conformación del ALCA hay obstáculos, frenos y lastres, pero también ilusión, impulso y voluntad de entendimiento. Entre los aspectos negativos tenemos las resistencias del Congreso de Estados Unidos y la actitud 
del Mercosur; entre los positivos la voluntad de Bill Clinton, Presidente de Estados Unidos, y el triunfo de la filosofía del libre cambio en el hemisferio, con la proliferación de acuerdos bilaterales y multilaterales de libre comercio.

Hoy en día, tras la crisis del peso mexicano, el libre comercio y la integración hemisférica resultan un objetivo difícil de defender ante el Congreso norteamericano; al ser México socio de Estados Unidos, junto con Canadá, en el NAFTA, éstos debieron financiar el peso para evitar la quiebra total de la economía mexicana, por lo que no es de extrañar la palpable resistencia del Congreso norteamericano a la incorporación de Chile al NAFTA. En Estados Unidos existe también preocupación acerca del impacto sobre los niveles internos de empleo y de salarios, dados los menores costes laborales de los demás países del hemisferio; así, por ejemplo, un jornalero chileno gana 7 dólares al día frente a los 9 dólares por hora del trabajador agrícola norteamericano, y un obrero chileno de una maquiladora gana 1,15 dólares por hora frente a los 13014 dólares por hora del trabajador industrial norteamericano. Son estos hechos los que justifican que el Presidente Clinton no consiguiese la autorización para negociar con fast track, ni la adhesión de Chile al NAFTA, ni la conformación del ALCA. El problema de la ausencia de vía rápida, que supone la aprobación o rechazo por el poder legislativo del acuerdo en un plazo de noventa días legislativos, no es otro que la posibilidad que existe en el Senado de impedir una votación por medio de paralizar el proyecto en una comisión o sostener debates interminables.

El otro obstáculo que tendrá que enfrentar la creación del ALCA es justamente la unificación, de manera armónica y beneficiosa para todos los países, de los diferentes intereses. Aquí un detalle importante fue que Brasil declinó participar en un encuentro de Viceministros de Comercio; y es que Mercosur venía llevando a cabo su unión aduanera y comercial con bastante éxito (hasta la crisis de real brasileño que frenó el proceso), habiendo alcanzado una integración en materia de infraestructuras (vial, portuaria, energética, etc.) así como la libre circulación de los individuos, la reválida educativa, la armonización de la justicia y de las normas laborales, entre otros objetivos. Por ello Mercosur ha defendido que las negociaciones del ALCA no empiecen por las reducciones arancelarias, que podrían poner en peligro su propia integración, sino que éstas sean tratadas en último lugar cuando ya todos los demás aspectos estén acordados, proponiendo al mismo tiempo una apertura paulatina, esto es que primero se aprueben las medidas que faciliten el intercambio comercial, luego se reformen los códi- 
gos de comercio o barreras no arancelarias y finalmente se discuta sobre los impuestos aduaneros. Otra de las propuestas de Mercosur fue la de la conformación, previa al ALCA, de un Área de Libre Comercio de Sudamérica (ALCSA) a partir de la extensión del propio Mercosur, para de esa forma negociar con mayor fortaleza frente a Estados Unidos y los países del NAFTA; el acuerdo de libre comercio entre Mercosur, Chile y Bolivia, con negociaciones para extenderlo a la Comunidad Andina, forma parte de esta estrategia. De hecho algunos analistas apuntaban la posibilidad de que se conformasen dos grandes bloques comerciales previos al ALCA, uno formado por el NAFTA, el MCCA, Caricom, Panamá, República Dominicana y, tal vez, Chile, y otro formado por el resto de los países sudamericanos agrupados en torno a Mercosur; no obstante, este escenario parece desdibujarse en la actualidad ante la pérdida de dinamismo de Mercosur, como consecuencia de la crisis del real brasileño, y el fuerte crecimiento económico de Estados Unidos, haciendo las veces de locomotora de la región. Frente a los intereses de Mercosur, los intereses norteamericanos han apuntado siempre justo en sentido inverso; es decir, Estados Unidos ha defendido, y ha logrado, que la discusión sea global y afecte al mismo tiempo a todos los temas que atañen al ALCA, incluyendo tarifas aduaneras y subsidios, como lo ponen de manifiesto los resultados de la Reunión Ministerial de Toronto a finales de 1999.

J unto a estos obstáculos, tenemos en primer lugar el interés del Presidente Clinton, que fue el impulsor de las negociaciones recogiendo la antorcha que le dejara Bush. Aunque Clinton, al igual que los mandatarios americanos que iniciaron las negociaciones, no será el Presidente en el año 2005, y esto puede restar voluntad en una negociación a fondo de las cuestiones, la posibilidad de que el Vicepresidente Gore pueda sucederle al frente de la Casa Blanca crea buenas expectativas para el ALCA. Como todo proceso de negociación a largo plazo requiere de un trabajo de equipo, donde las ideas estén por encima de las voluntades presidenciales, por ello la permanencia de los demócratas en el gobierno norteamericano puede favorecer al ALCA. Y aunque se produjese una alternancia, no olvidemos que fue el presidente George Bush, padre del candidato republicano, quien lanzó la Iniciativa para las Américas.

Respecto al impulso y la ilusión puesta en el proceso por el resto de los países del hemisferio, da muestra la proliferación de los acuerdos de libre comercio en la región, rompiendo con la idea de esquemas de integración de mayor alcance. Los países latinoamericanos y caribeños han abrazado en su mayoría la filosofía del neoliberalismo y han depositado muchas de sus 
esperanzas de desarrollo en el ALCA; esperemos que el futuro no les decepcione.

Después de todo lo que hemos estado analizando en este documento parece evidente que desde el final de la Guerra Fría algo ha cambiado en las relaciones hemisféricas. El proyecto del ALCA es de por sí una puerta abierta que permite pasar de un escenario geopolítico de imperialismo a otro de panamericanismo. El proyecto de ALCA es también una sutura con la que cerrar viejas heridas en las relaciones hemisféricas. En los albores del siglo $\mathrm{XXI}$, en las Américas se están abriendo puertas y cerrando heridas; pero aunque las puertas se abran, atravesarlas tiene su coste, y además aún persiste una puerta cerrada y una herida abierta, las de Cuba.

\section{BIBLIOGRAFÍA}

AlcA (1998-a): “Antecedentes", en www.ftaa-alca.org.

AlCA (1998-b): “Declaración Ministerial de San J osé”, en www.ftaa-alca.org. AlCA (1999): “Declaración Ministerial de Toronto", en www.ftaa-alca.org.

BID (1997): “Estimaciones preliminares de las exportaciones de las subregiones de América: 1996", en www.iadb.org.

BID (1999): “Nota Periódica sobre Integración y Comercio en las Américas”, en www.iadb.org.

Bulmer-Thomas, V. (1997): Integración económica de las Américas, San José, Asamblea Legislativa de la República de Costa Rica, mimeo.

Cepal (1994): El regionalismo abierto en América Latina y el Caribe. La integración económica al servicio de la transformación productiva con equidad, Santiago de Chile, Naciones Unidas-CEPAL.

Cinco Días (1998): "América se compromete en la lucha contra la exclusión social", Economía Internacional, en Cinco Días, 20/4/1998.

EDwARDS, S. (1997): Crisis y reforma en América Latina. Del desconsuelo a la esperanza, Buenos Aires, Emecé Ed. (10 ed. 1995).

GITLI, E. (1991): La Iniciativa de las Américas y sus implicaciones para las negociaciones latinoamericanas, Cuadernos de Política Económica, Maestría en Política Económica, Heredia (Costa Rica), Universidad de Nacional. 
Hidalgo Capitán, A. L. y Cubillo Guevara, A. P. (1999): “El AlCA, el marco de las relaciones económicas entre Estados Unidos y América Latina en el siglo $X X I$ ", en DE PAZ, M. A. et al., Economía Mundial. Docencia e Investigación, Huelva, Servicio de Publicaciones de la Universidad de Huelva.

J AUBERTH Rojas, H. R. et al. (1991): La triangulación. Centroamérica-MéxicoEUA. "Una oportunidad para el desarrollo y la paz?", San J osé (Costa Rica), DEI, CRIES, PACCA, CIDE, (1ํod. 1990).

PreBISH, R. (1998): “Dependencia, interdependencia y desarrollo", Revista de Ia CEPAL, no 34, pp. 206-212, (1ㅇed. 1986).

Rojas Aravena, F. (ed.) (1993): América Latina y la Iniciativa para las Américas, Santiago (Chile), FLACSO.

Skidmore, T. y Sмıтн, P. (1996): Historia Contemporánea de América Latina en el siglo XX, Barcelona, Crítica.

SelA (1997): “Tendencias y opciones en la integración de América Latina y el Caribe", en www.sice.oas.org/ forum.

Sela (1998): “Opciones de Estados Unidos en el Área de Libre Comercio de las Américas", en www.sice.oas.org/ forum.

Sobole, A. (1997): ALCA: "Qué nos espera?", Maestría Centroamericana de Ciencias Políticas, San José, Universidad de Costa Rica, mimeo.

VACCHINO, J. M. (1997): "Opciones estratégicas en materia de apertura al exterior", en www.assnat.qc.ca/copa/forces/ espagnol/article5.html. 